\title{
Diz çevresi osteotomilerinden sonra total diz protezi uygulamaları
}

\section{Total knee replacement applications after knee osteotomies}

\author{
Can Doruk Basa ${ }^{1}$, Elcil Kaya Biçer², Semih Aydoğdu², Hakkı Sur ${ }^{2}$ \\ 1Sağlık Bilimleri Üniversitesi Tepecik Eğitim ve Araştırma Hastanesi Ortopedi ve Travmatoloji Kliniği, İzmir \\ ${ }^{2}$ Ege Üniversitesi Tıp Fakültesi Ortopedi ve Travmatoloji Anabilim Dalı, İzmir
}

Yüksek tibial osteotomi (YTO) tek medial kompartman diz artrozlu, varus dizilimi olan genç hastalarda ağrıyı geçirmek, total diz protezi (TDP) ameliyatını geciktirmek veya total diz protezi ameliyatı gereksinimini ortadan kaldırmak için uygulanan bir ameliyattır. Her ne kadar osteotomiyi uygularken, amaç artroplasti gereksinimini ortadan kaldırmak olsa da bazı hastalarda artroplastiye gidiş kaçınılmazdır. Tüm revizyon ameliyatlarında olduğu gibi YTO sonrası TDP uygulaması da bir takım teknik detaylar içermektedir. Ameliyata başlarken uygulanacak insizyondan, kemik kesilere hatta kullanılacak protezin seçimine kadar teknik incelikler ve farklılıklar mevcuttur. Bu farklıııklar daha önce uygulanmış olan YTO'nun tipine göre de değişmektedir. YTO sonrası uygulanan TDP'de femoral taraf kemik kesilerinde ve implant seçiminde primer artroplastiye göre farklılık bulunmazken, bazen tibial tarafta osteotomi hattını geçen uzun stem kullanımı gerekebilmektedir. YTO sonrası uygulanan TDP ile primer TDP arasında benzer klinik sonuçlar ve komplikasyon oranları olmakla birlikte, YTO sonrası TDP'de primer total diz artroplastisine göre revizyon oranları artabilmektedir.

Anahtar sözcükler: yüksek tibial osteotomi; total diz protezi; revizyon diz artroplastisi
High tibial osteotomy (HTO) is frequently used to treat young patients with medial compartment knee arthrosis and varus alignment with the goal of pain relief, delay or eliminate the need for total knee arthroplasty (TKA). Although the aim of performing osteotomy is to eliminate the need for arthroplasty, revision to arthroplasty is inevitable in some patients. As in all revision operations, TKA procedure after HTO includes some technical details. There are technical differences including incision and even the selection of the prosthesis to be used during the operation. These differences also vary according to the type of HTO applied before. Long stem tibial components crossing the osteotomy gap may sometimes be required. Although there are similar clinical outcomes and complication rates between TKA with or without prior HTO; revision rates might be increased in TKAs after HTO compared with primary total knee arthroplasties.

Key words: high tibial osteotomy; total knee arthroplasty; revision knee arthroplasty
$\mathbf{Y}$ üksek tibial osteotomi (YTO), varus dizilimi ve izole medial kompartman osteoartriti olan genç ve aktif bireylerde uygulanmaktadır. Kubbe tipi, kapalı kama ve açık kama olmak üzere üç farklı YTO tekniği bulunmaktadır. Günümüzde kilitli, rijit plakların ulaşılabilir olmasıyla açık kama osteotomiler diğerlerine göre daha çok tercih edilmektedir. Uygulanan teknikten bağımsız olarak YTO, izole medial kompartman osteoartritinin tedavisinde klinik ve radyolojik açıdan oldukça başarılı sonuçlar vermektedir; ancak yine de olguların izleminde çeşitli sebeplerle total diz protezine (TDP) dönüşüm gereksinimi ortaya çıkabilmektedir. ${ }^{[1]}$ Bu derlemede, TDP dönüşümü gerektiren YTO'ların epidemiyolojisi, cerrahi teknik özellikleri, klinik sonuçları ve komplikasyonlarının uygulanmış olan osteotomi tipi göz önünde bulundurularak gözden geçirilmesi amaçlanmıştır.

\section{EPIDEMIYOLOJi}

YTO ile TDP gereksinimini ortadan kaldırmak hedeflense de, bu her zaman mümkün olamamaktadır. Insall ve arkadaşları yaptıkları çalışmada YTO sonrası TDP gerekliliğinin \%23 olduğunu belirtmişlerdir. ${ }^{[2]} \mathrm{Bu}$ oran çeşitli çalışmalarda \%8 ile \%31 arasında değişmektedir. ${ }^{[3-5]}$ YTO'nun sağkalım oranlarına ilişkin yapılmış olan çalışmalarda beş yıllık oran \%89 (\%95 güven aralığında (GA) 88-90), 10 yıllık oran \%73 (\%95 GA 72-75), 15 yıllık oransa $\% 56$ olarak bildirilmiştir. ${ }^{[4,6]}$

- İletişim adresi: Prof. Dr. Semih Aydoğdu, Ege Üniversitesi Tıp Fakültesi Hastanesi, Ortopedi ve Travmatoloji Anabilim Dalı, 35100, Bornova, İzmir Tel: 0542 - 4259818 e-posta: semih.aydogdu@ege.edu.tr

- Geliș tarihi: 20 Ocak 2020 Kabul tarihi: 22 Șubat 2020 


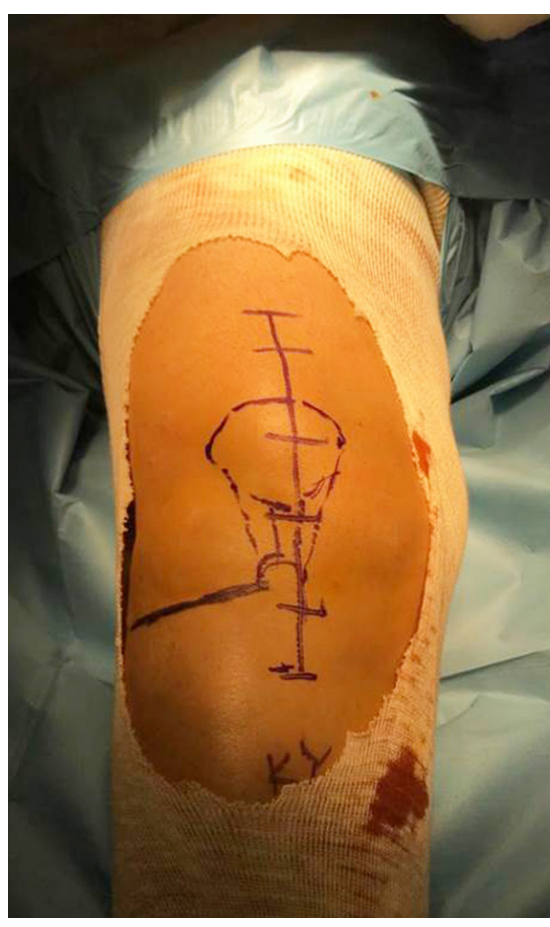

Şekil 1. Kapalı kama osteotomisi için yapılmış olan lateral transvers insizyon, TDP için planlanan anterior orta hat insizyonu görülüyor.

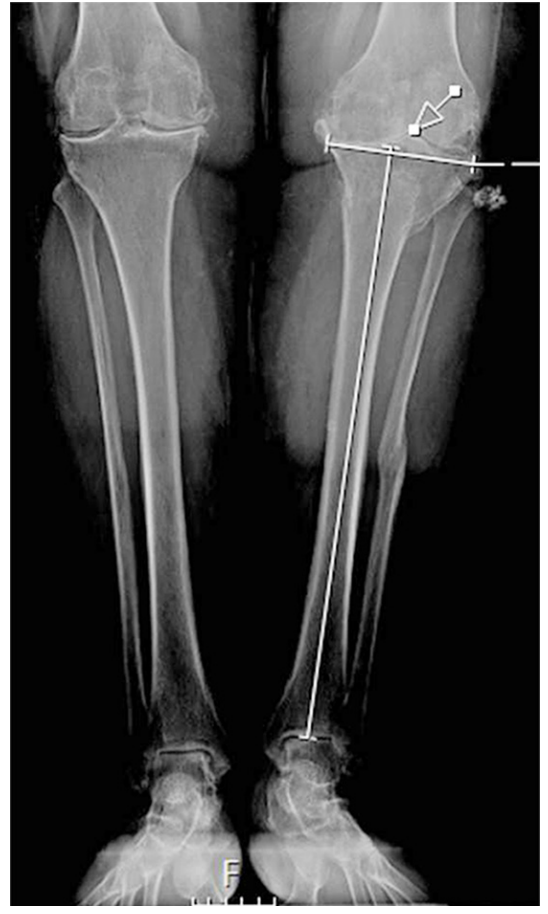

Şekil 2. Sol dizde kubbe tipi osteotomi sonrası TDP planlamaSI; eminensiyalar okla gösterilmiştir. İntramedüller tibia kesisi yapmak için ilk giriş yeri olarak eminensiyaların önü seçilirse, kılavuzu ilerletmenin mümkün olamayacağı direk grafide görülmektedir.
Elbette ki osteotomi sonrası yetersiz düzeltme veya fazla düzeltme gibi faktörler başarısız sonuçlarla ilişkili olsa da Keenan ve arkadaşları ileri yaş ve kadın cinsiyetin artroplastiye erken dönüşüm için bağımsız kolaylaştırıcı faktörler olduklarını ortaya koymuşlardır. ${ }^{[6]}$ Khoshbin ve arkadaşları da bu çalışmayı destekler şekilde 46 yaşını eşik değer olarak saptamışlar; ileri yaş, kadın cinsiyet, yüksek komorbidite indeksi, geçirilmiş artroskopi ya da menisektomi öyküsü olmasının TDP gereksinim riskini arttırdığını göstermişlerdir. Bununla birlikte YTO ile eş zamanlı bağ rekonstrüksiyonu yapılmasının bu riski azalttığını saptamışlardır. ${ }^{[7]}$

\section{CERRAHI PLANLAMA}

Primer TDP ile karşılaştırıldığında YTO'dan sonra TDP yapılması teknik olarak kendine özgü bazı zorlukları beraberinde getirir. Bu teknik zorluklar, uygulanmış olan osteotomi tipine göre değişkenlik gösterir. Kapalı kama ve kubbe tipi YTO'larda proksimal tibianın geometrisinde değişiklik olmaktadır. Ayrıca, proksimal ve distal parçanın birbirinden tamamen ayrılmış olduğu kubbe tipi osteotomide istenen düzeltme sağlandıktan sonra özellikle sagittal planda yeni bir deformite oluşabilmektedir. Kapalı kama YTO'da, dizilimdeki düzeltme proksimal tibia metafizinden kama çıkarılmasıyla sağlandı̆̆ından, bu bölgedeki kemik stoğu azalmaktadır. Medial açık kama YTO, bu iki tekniğe göre proksimal tibia geometrisini çok daha az değiştirir; ayrıca kemik stoğu korunur. Diğer iki osteotomi tipiyle karşılaştırıldığında, açık kama YTO sonrası TDP, teknik olarak daha az problemli görünmektedir. ${ }^{[1]}$

Uygulanmış olan YTO tipinden bağımsız olarak başarılı bir TDP için iyi bir cerrahi planlama ve hazırlık yapılması esastır. Hazırık insizyon planlamasından eklem açlımına, ligament dengesi kurulmasından komponent seçimine kadar ayrıntılı şekilde dikkatlice yapılmalıdır. Artroplastide kullanılacak insizyon için önceki insizyonlar değerlendirilmelidir (Şekil 1). Dizde birden çok vertikal insizyon varsa lateraldeki insizyon seçilmeli, eğer bu insizyon artroplasti için uygun değilse uygulanacak insizyon ile eski insizyon arasında en az $6 \mathrm{~cm}$ olmasına özen gösterilmelidir. ${ }^{[8]}$

Ameliyat öncesi (Preoperatif) dönemde hastanın radyografik değerlendirmesi için, yüklenmede bacak uzunluk grafileri ve yine yüklenmede ön arka ve yan diz grafileri çekilmelidir. Bacak uzunluk grafilerinde alt ekstremitenin mekanik eksen sapması, femurun anatomik ve mekanik eksen farkı ölçülmelidir. Bu grafilerde dikkat edilmesi gereken önemli bir nokta, tibianın anatomik eksenidir. Tibia kesisinin intramedüller kılavuz yardımıyla yapılması planlanıyorsa, tibianın anatomik ekseninin eklem yüzeyinde hangi noktayı kestiği önemlidir (Şekil 2). İntramedüller kılavuz için ilk giriş yeri olarak, klasik lokalizasyon yani tibial çıkıntıların önü 

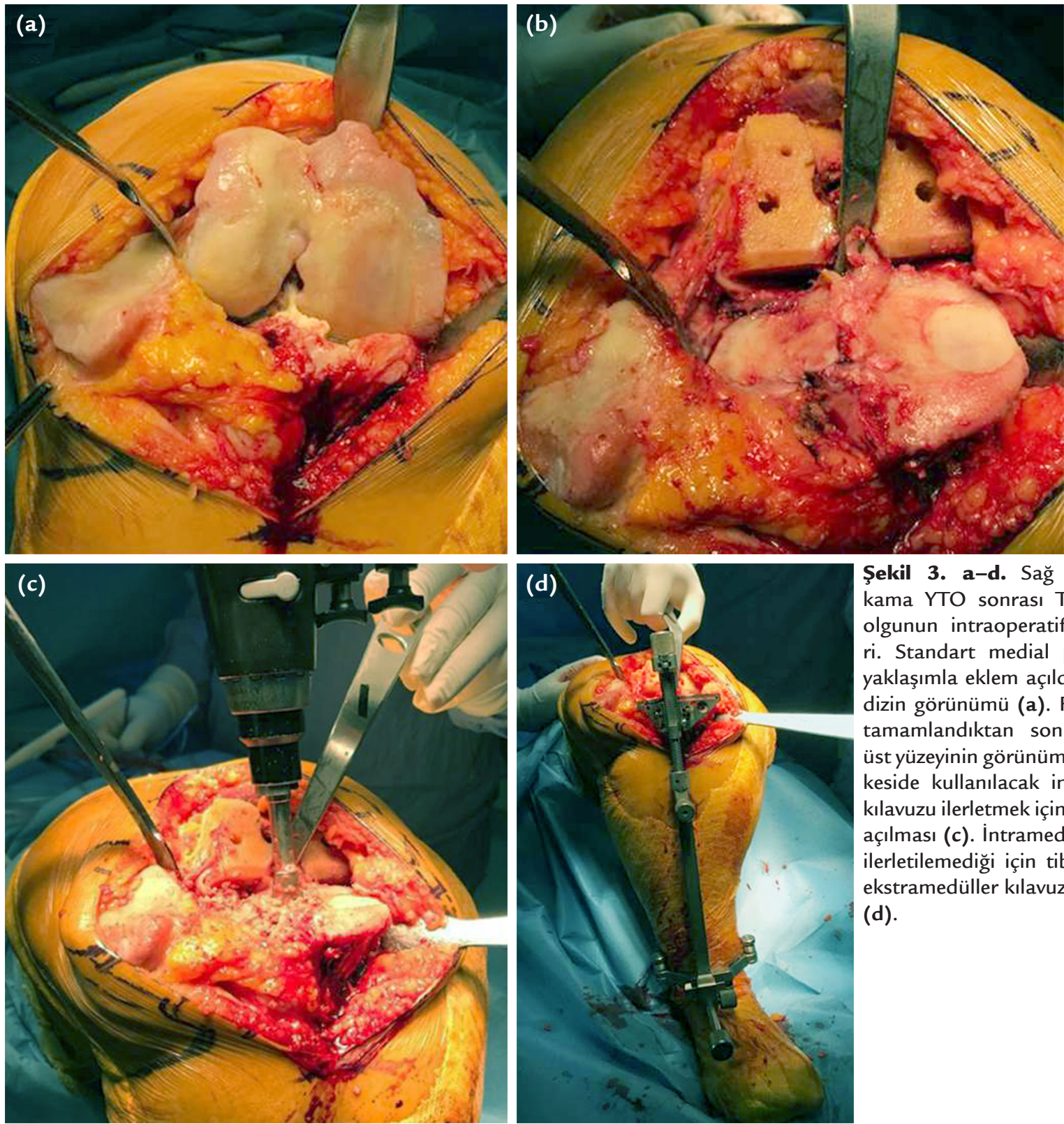

Şekil 3. a-d. Sağ dize kapalı kama YTO sonrası TDP yapılan olgunun intraoperatif görüntüleri. Standart medial parapatellar yaklaşımla eklem açıldıktan sonra dizin görünümü (a). Femur kesisi tamamlandıktan sonra, tibianın üst yüzeyinin görünümü (b). Tibial keside kullanılacak intramedüller kılavuzu ilerletmek için giriş yerinin açılması (c). İntramedüller kılavuz ilerletilemediği için tibia kesisinin ekstramedüller kılavuzla yapılması (d).

seçilecek olursa ve tibianın anatomik ekseninde sapma varsa yani bu ilk giriş yerinden geçmiyorsa, kılavuzu medulla içinde ilerletmek mümkün olamayacaktır. Tibial kesi, yeterince ilerletilmemiş kılavuzlar baz alınarak yapılırsa anatomik eksene dik olamayacaktır. Bu nedenle, ameliyat öncesi grafiler üzerinde intramedüller kılavuz için uygun ilk giriş yeri belirlenmelidir. Bu sorun pek tabi ki, ekstramedüller tibial kesi kılavuzları kullanılarak da aşılabilir (Şekil 3). Fakat bu grafilerde dikkat edilmesi gereken bir diğer nokta da YTO'dan sonra gerek frontal gerek sagittal plandaki değiş̧en proksimal tibia geometrisidir. Tibial kesi ekstramedüller kılavuz yardımıyla yapılabilir; fakat anatomik değişiklikler protezin sap kısmının lateral kortekse takılmasına yol açabilir. Ameliyat öncesi grafiler üzerinde standart saplı bir diz protezinin yerleştirilip yerleştirilemeyeceği etüt edilmelidir. Hem ön-arka hem de yan grafiler üzerinde şablonlama yapılmalıdır (Şekil 4).

Ameliyat öncesi dönemde patellanın mobilitesi klinik olarak değerlendirilmeli ve yan grafilerde patellar yükseklik ölçümü yapılmalıdır (Şekil 5). YTO'dan sonra ameliyat sonrası (postoperatif) immobilizasyona 


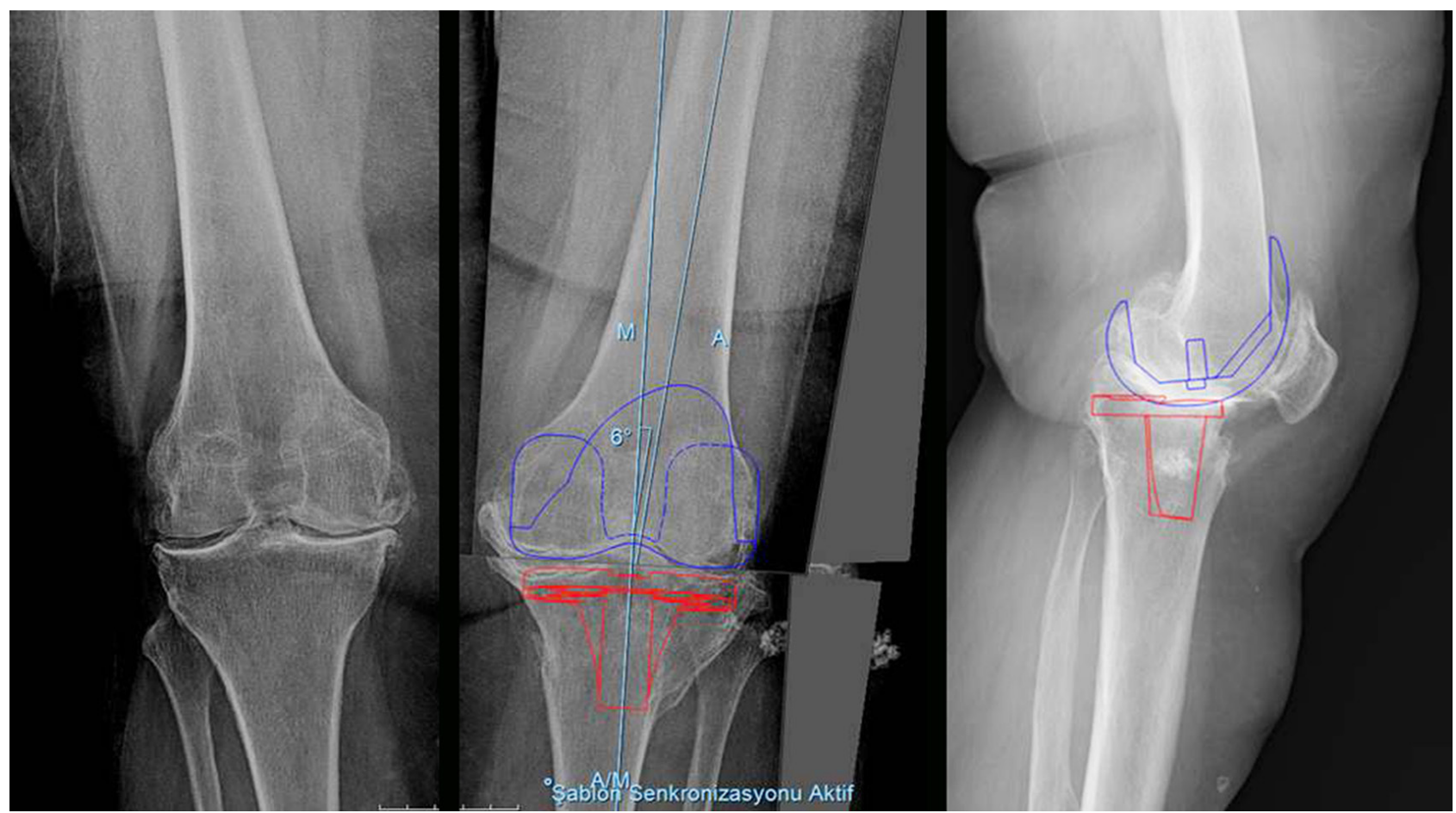

Şekil 4. Sol dizine daha önce kubbe tipi YTO yapılmış bir olguda ön arka ve yan grafiler üzerinde ameliyat öncesi (preoperatif) şablonlama.

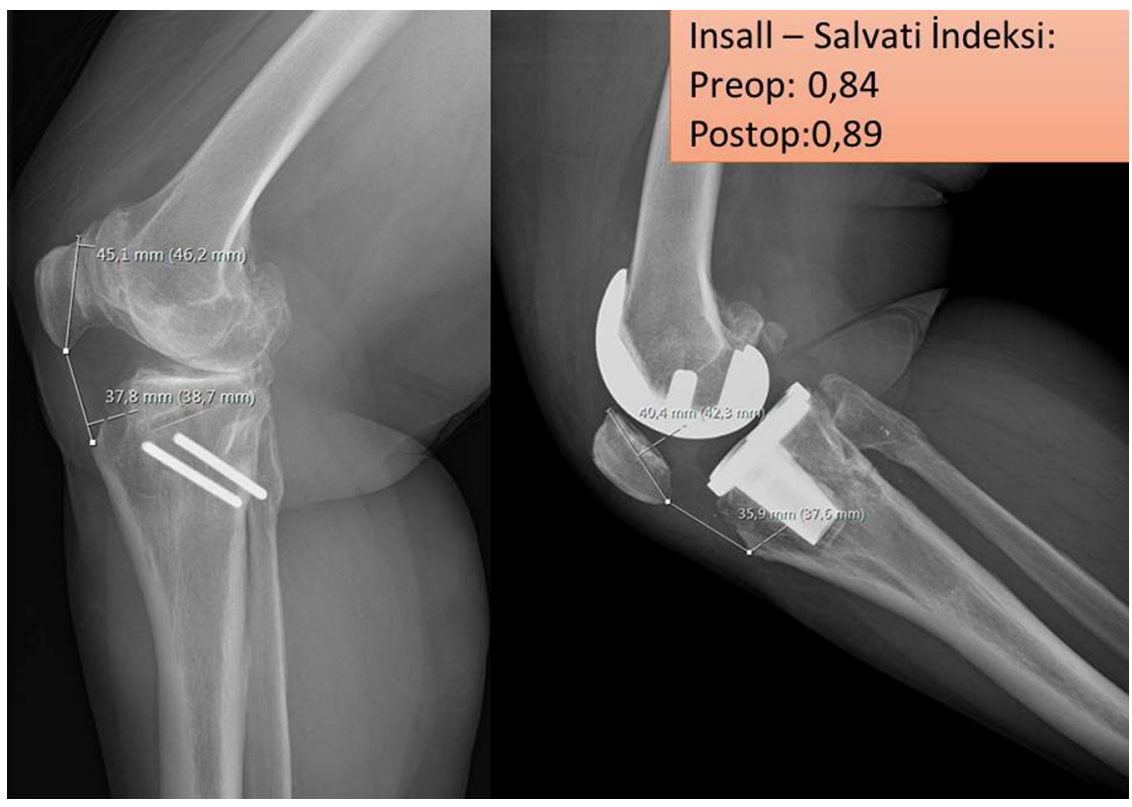

Şekil 5. Sağ dizine kapalı kama YTO yapılmış olguda TDP'den önce ve sonra yan grafiler üzerinde Insall-Salvati indeksinin ölçülmesi.

ve patellar tendondaki yapışıklıklara bağlı olarak patellanın yüksekliği değişebilmektedir. Klasik bilgi olarak kapalı kama YTO'dan sonra patellar yükseklik artmakta, açık kama YTO'dan sonra ise azalmaktadır. Patellayı döndürmede sorun yaşanabileceği göz önünde bulundurulmalı, bu olasılık dâhilinde gereğinde genişletilmiş yaklaşımları uygulamaya hazırlıklı olunmalıdır.

YTO'nun tespitinde kullanılan implantın çıkarılabilmesi için uygun tornavida sağlanmalıdır. Arka çapraz bağı koruyan ve kesen protez seçenekleri, tibial uzatma stemleri hazır bulundurulmalıdır. 


\section{Cerrahi Özellikler}

YTO'da kullanılmış olan implantlar, tibial kesinin kolaylıkla yapılabilmesi için çıkartılmalıdır. Bu implantların çıkartılma zamanı tartışmalıdır. Eğer YTO'daki başarısızlık nedeninin enfeksiyon olduğu düşünülüyorsa artroplasti iki aşamalı olmalıdır. Önce implant çıkartılıp mikrobiyolojik örneklemeler yapılmalı, ardından ikinci aşamada enfeksiyon tamamen tedavi edilmişse artroplasti uygulanmalıdır. Ameliyat sırasında tibialis anterior kasının (kapalı kama YTO için) veya medial kollateral ligamentin (açık kama YTO için) implantlar çıkartılırken fazla zarar gördüğü ve bunun rehabilitasyonu yavaşlatabileceğinin öngörüldügüu durumlarda artroplasti başka bir seansa bırakılabilir. ${ }^{[1]}$

İnsizyon sonrası eklem yaklaşımı daha önce uygulanmış olan YTO'ya bağlı olarak değişiklik gösterebilmektedir. YTO sonrası sağlanan fazla düzeltmede kayıp varsa yani genu varum deformitesi gelişmişse, medial parapatellar artrotomi ile ekleme ulaşılır; fazla düzeltmeye bağlı valgus dizilim varlığında, deformite pasif olarak düzelmiyorsa lateral parapatellar yaklaşım uygulamak gerekebilir. ${ }^{[1]}$ YTO sonrası (özellikle kapalı kama YTO) olan patella baja ve patella çevresinde olan yapışıklıklar da patellayı everte etmekteki birtakım zorlukları beraberinde getirmektedir (Şekil 5). Patellar tendon avulsiyonları, patella kırıkları gibi komplikasyonların gelişmemesi için tibial tüberkül osteotomisi, kuadriseps $\mathrm{V}$-Y plasti veya rektus snip uygulanabilmektedir. ${ }^{[9,10]}$ Bazı yazarlar ise yaklaşımda gerekecek ek girişimlerin osteotomi sonrası gecikmiş veya yetersiz rehabilitasyona bağlı oluşan patellar tendon kısalığına bağlı olarak geliştiğini, osteotomi sonrası yeterli tespit ve uygun rehabilitasyonun uygulanmasının artroplastide gevşetmeler dışında ek girişim gerekliliğini ortadan kaldırdığını düşünmektedir. [11]

Yüksek tibial osteotominin tipi ile sonrasında uygulanacak olan artroplasti arasında da ilişki bulunmaktadır. Uygulanmış olan osteotominin açık kama YTO olması durumunda osteotominin şekli nedeniyle proksimal tibia metafiz anatomisi pek de fazla değişmemektedir (Şekil 6). Ancak kapalı kama ya da kubbe tipi YTO uygulanmış hastaların değişmiş olan proksimal tibia anatomisi ve geometrisi uygulanacak olan artroplastiyi özellikli kılmaktadır (Şekiller 7-11). Açık kama ve kapalı kama YTO sonrası TDP uygulanan hastalar değerlendirildiğinde kapalı kama YTO sonrası uygulanan TDP'lerde tibial tüberkül osteotomisi gereksinimi daha fazla olabilmektedir; lateralde osteotomiye bağlı oluşmuş yapışıklıkların giderilmesi için gevşetme yapılması ve bunu dengelemek için medialden de gevşetme yapılması gerekmektedir. ${ }^{[9,12]}$
YTO sonrası tibia anatomisinde değişiklikler, koronal veya rotasyonel deformiteler görülebilmektedir. Posterior tibial eğim YTO uygulanmış hastalarda değişebilmektedir. Artroplasti öncesi bu deformitelerin iyi analizi gerekmektedir. Ciddi kemik defektleri veya dizilim kusurları olmadıkça çoğu deformite intraartiküler kesiler ile düzeltilmeye çalışılmaktadır. Ancak ciddi rotasyonel deformiteleri olan kişilerde tibial komponent uygulamalarında yapılacak modifikasyonlar patellofemoral ve tibiofemoral kinematikte bozulmalara neden olabilmektedir. Bu durumlarda rotasyonel osteotomiler veya tibial tüberkül medializasyon osteotomileri uygulanabilir. ${ }^{1]}$

Artroplasti sırasında kemik kesilerin yapılması sırasında en büyük problem anatomik kılavuz noktaların ortadan kaybolmuş olmasıdır. Tibial kemik kesinin tibia mekanik aksına dik mi yoksa metafizyel anatomiye uygun mu yapılacağına karar verilmelidir. Metafizyel anatomiye göre yapılacak kesiler alt ekstremite dizilim bozukluğuna yol açabilir. Tibia mekanik aksına dik yapılacak kesilerle de bozulmuş metafizer anatomiye bağlı tibial komponentin ucunun lateral tibia korteksine sürtünmesi ile karşılaşılabilir. Bu durumlarda bir küçük boy tibial komponent tercih edilebilir; komponentin medialize edilerek yerleştirilmesi iç yan bağda sıkışmaya yol açabileceğinden gerekmedikçe tercih edilmemelidir. ${ }^{[11]}$ Standart tibial komponentin kullanılamayacağı olgularda bir diğer seçenek de offsetli tibial baseplate ya da hastaya özel yaptırılmış (custom-made) protezlerin tercih edilmesidir. Diğer kemik kesi problemi ise posterior tibial eğimin ayarlanmasıdır. Klasik olarak, önlem alınmazsa posterior tibial eğim kapalı kama osteotomisi ile azalmakta, açık kama ile artmaktadır. Özellikle kapalı kama YTO sonrası posterior tibial eğimin ayarlanması hasta klinik sonuçları açısından çok önemlidir. Tibial eğimin artmış olması anterior instabiliteye neden olabilmektedir. Azalmış eğim ise fleksiyon kısıtlılığına neden olabilmektedir. ${ }^{[1]}$

Kemik kesiler tamamlandıktan sonra yumuşak doku dengesi tamamlanmamış olabilir. Özellikle tekrar oluşmuş olan varus deformiteli dizlerde medial kemik blok çok ince lateral kemik blok daha kalın olabilir. Bu durumlarda medial yapıların gevşetilmesi gerekli olabilmektedir. Tibial metafizyel düzeltmenin $10^{\circ}$ 'nin üstünde olduğu vakalarda ise medial gevşetmenin daha agresif yapılması gerekli olmaktadır. Bunun da üstündeki deformitelerde gevşetmelere ek olarak eklem dışı düzeltici osteotomiler veya menteşeli protezler gerekebilmektedir. ${ }^{[1,13]}$

YTO sonrası uygulanan artroplastilerde implant seçiminde de özenli davranılması gereklidir. Uygulanmış olan YTO sonrası arka çapraz bağın yetmezliğinin olabileceği ve arka çapraz bağ kesen protezlerin tercih 

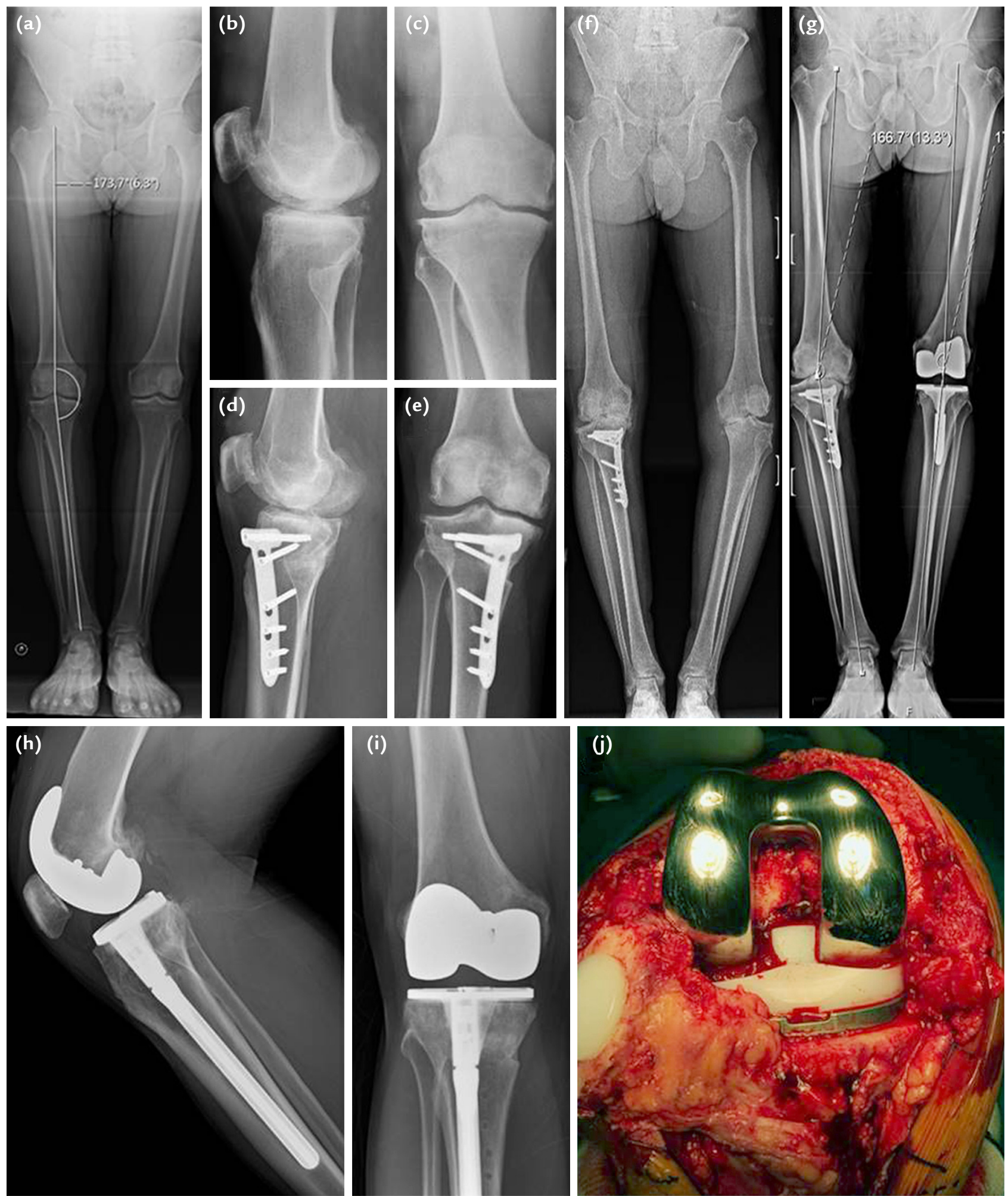

Şekil 6. a-j. Açık kama YTO üstüne TDP olgusu. Olgunun ameliyat öncesi bacak uzunluk, yüklenmede ön-arka ve yan grafileri (ac). Medial eklem osteoartriti tanısıla açık kama YTO uygulandıktan sonra çekilen ön arka ve yan grafileri (d-e). İzlemde hastanın her iki dizinde hızlı bir dejeneratif sürecin geliştiği görülüyor (f). YTO'dan üç yıl sonra sol dize TDP yapıldı (g). YTO'dan dört yıl sonra sağ tarafta aynı seansta implant çıkarılıp uzatma stemli posterior stabilize TDP uygulanıyor. Medial tibial platodaki defekt otolog kemik greftiyle greftlendi (h-i). TDP’nin ameliyat sırasındaki (intraoperatif) görünümü. Patellar yüzeyin de değiştirilmiş olduğu görülüyor (j). 

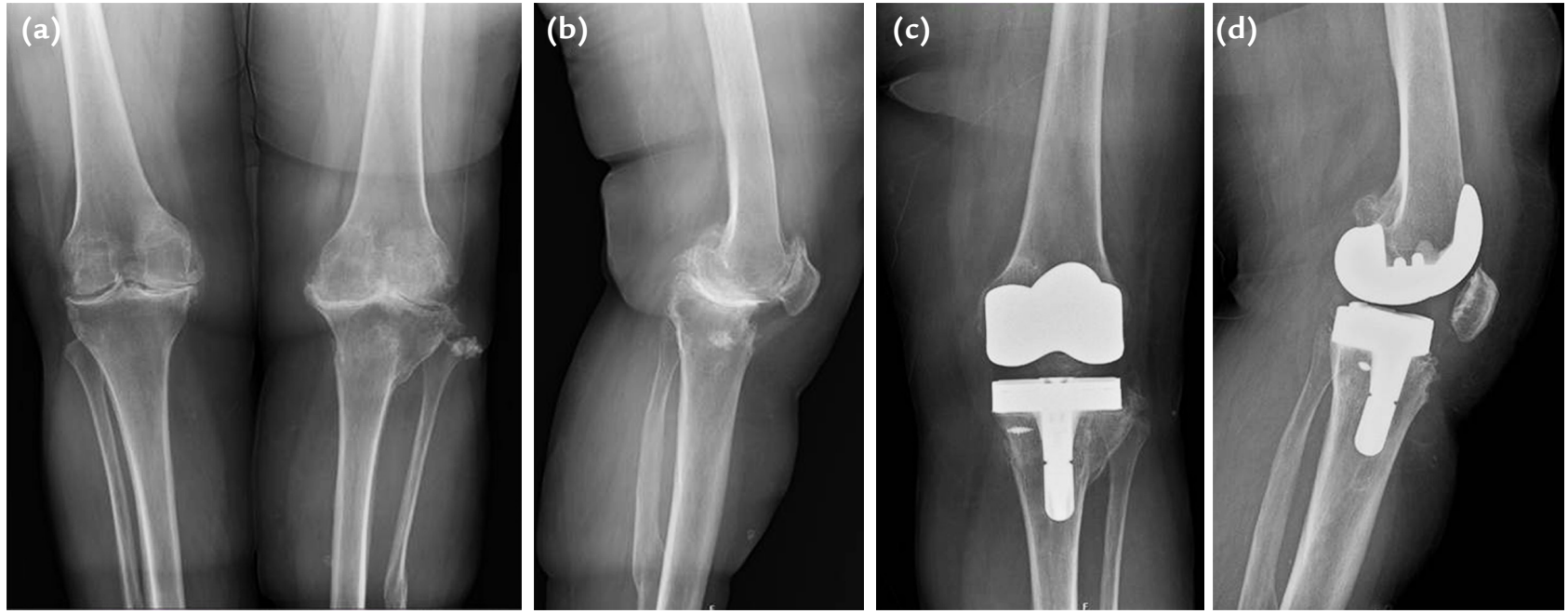

Şekil 7. a-d. Sol dize kubbe osteotomisi üstüne TDP olgusu. Ameliyat öncesi ön-arka ve yan grafilerde proksimal tibianın geometrisindeki değişiklikler görülmektedir $(\mathbf{a}, \mathbf{b})$. Ameliyat sonrası ön-arka ve yan grafilerde, tibial tarafa hem medial hem lateral blok ve kısa uzatma stemi tercih edilmiştir. Çapa dikiş kullanılarak iç yan bağ onarımı yapılmıştır (c, d).
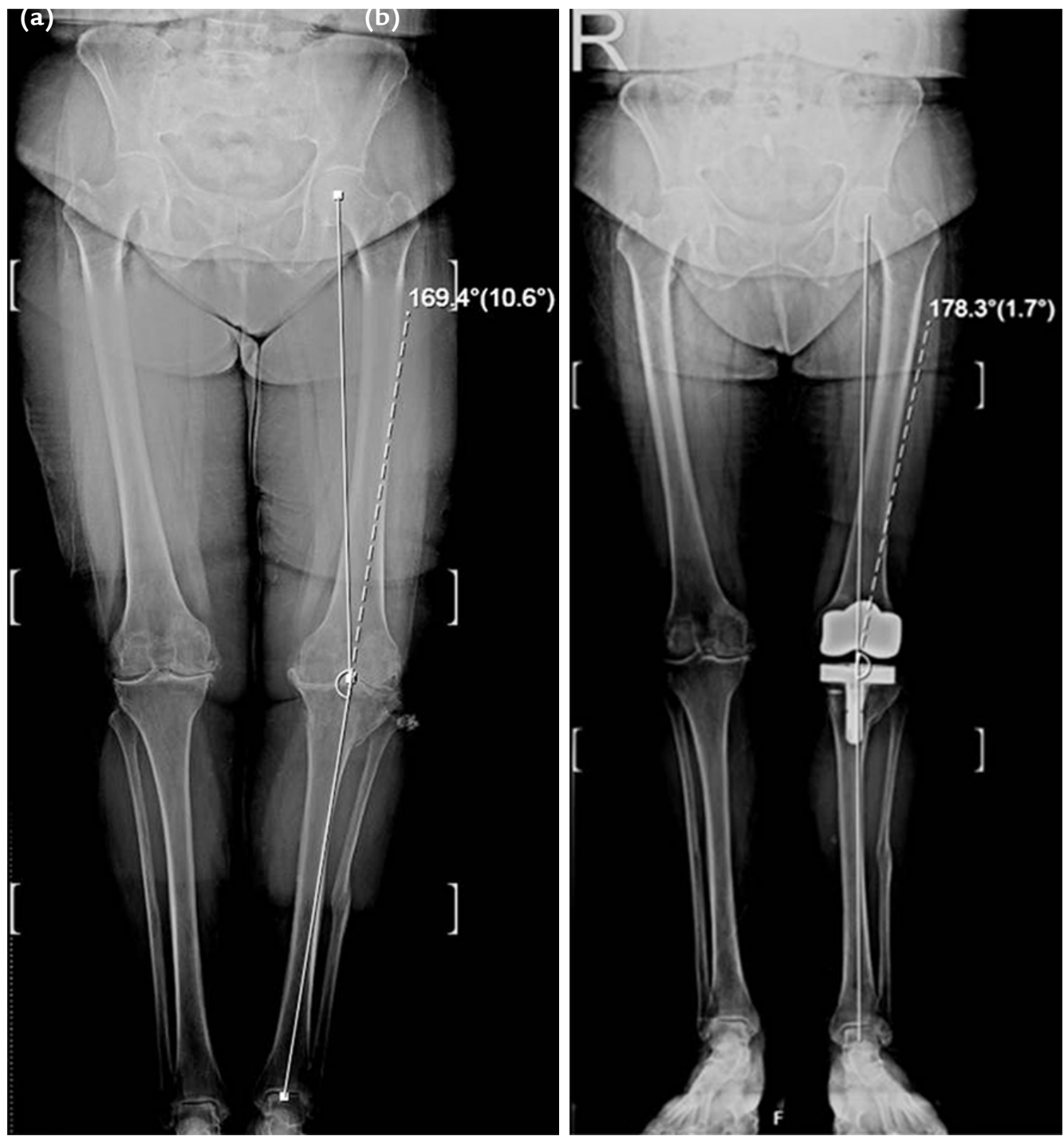

Şekil 8. a, b. Şekil 7'deki olgunun preop (a) ve postop (b) bacak uzunluk grafilerinde alt ekstremitenin mekanik eksen sapmasının $10,6^{\circ}$ varustan, $1,7^{\circ}$ valgusa düzeltildiği görülüyor. 

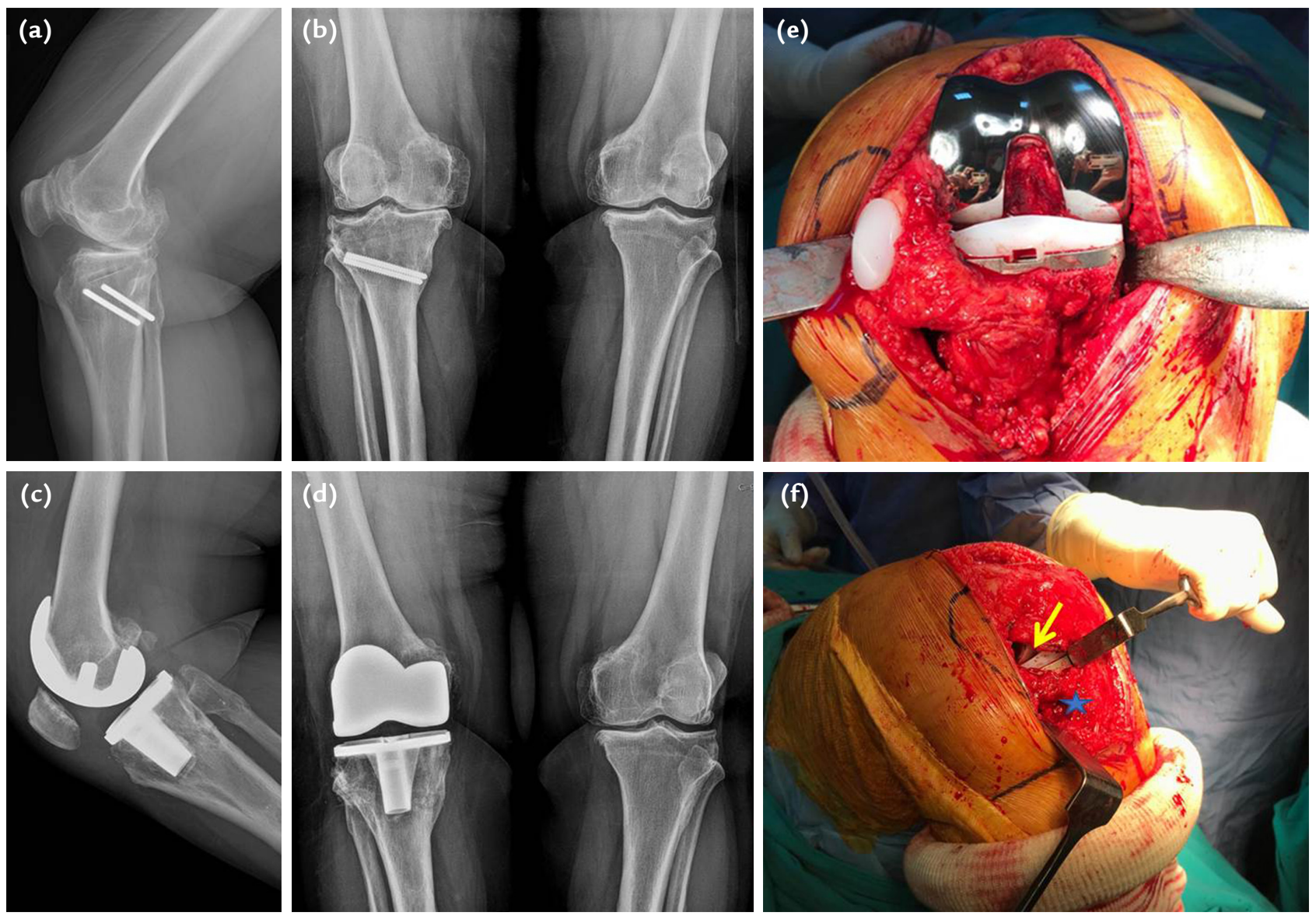

Şekil 9. a-f. Sağ diz kapalı kama YTO üstü TDP olgusu. Olgunun ameliyat öncesi yan ve ön-arka grafilerinde kapalı kama YTO'nun tespitinde kullanılmış ancak kırıldığı için plakla birlikte çıkarılmamış iki adet vida mevcut (a, b). TDP sonrası yan ve önarka grafiler (c, d). TDP’nin ameliyat esnasındaki görünümü (e). Lateral retinaküler gevşetme sarı okla, kırık vidaların çıkarıldığı bölge mavi yıldızla gösterilmiştir (f).

edilmesi gerektiği düşünülmektedir. ${ }^{[14]}$ Ayrıca YTO sonrası uygulanan artroplastilerde arka çapraz bağ koruyan ve kesen protez kullanılan olguların karşılaştırılmasında, arka çapraz bağ koruyan protezlerde orta dönemde diz fonksiyonel skorlarının ve eklem hareket açıklığının daha kötü olduğu gösterilmiştir. ${ }^{15]}$ Artroplasti sırasında patellar komponentin de uygulanması önerilmektedir. Patellar komponentin uygulanmadığı olgularda devam eden diz önü ağrısı görülebilmektedir. ${ }^{[16]}$

\section{KLINIK SONUÇLAR}

YTO sonrası TDP bazı teknik zorluklara sahip olsa da klinik ve radyografik sonuçları bakımından primer TDP'lerle benzer bulunmuştur. ${ }^{[16-18]}$ Ramappa ve arkadaşları tarafından yapılmış olan bir sistematik derleme ve meta-analizde klinik sonuçlar bakımından diz protezi öncesi YTO uygulanmış olan ve olmayan gruplar arasında anlamlı bir fark bulunmamıştır. Ortalama 7,2 yıl izlem süresi sonunda, herhangi bir nedenle revizyon TDP yapılmış olması son nokta olarak kabul edildiğinde, öncesinde YTO uygulanmış olan grupta sağkalım oranı \%95, uygulanmamış gruptaysa \%97'dir. Revizyon için aseptik gevşeme son nokta olarak kabul edildiğinde, her iki grubun sağkalım oranı \%98 bulunmuştur. Bu sistematik derleme ve meta-analizde bazı teknik zorlukları olsa da geçirilmiş YTO'nun ilerleyen yıllarda yapılacak olan TDP'yi olumsuz yönde etkilemediği sonucuna varılmıştır. ${ }^{[19]}$ Daha güncel bir başka meta-analiz çalışmasında önceden YTO uygulanan ve uygulanmayan YTO grupları arasında kısa-orta dönemde klinik sonuçlar, operasyon süresi, Insall-Salvati indeksi, komplikasyon oranları ve sağkalım oranları bakımından fark bildirilmemiştir Kısa-orta dönemli sağkalım oranları YTO üstü TDP 

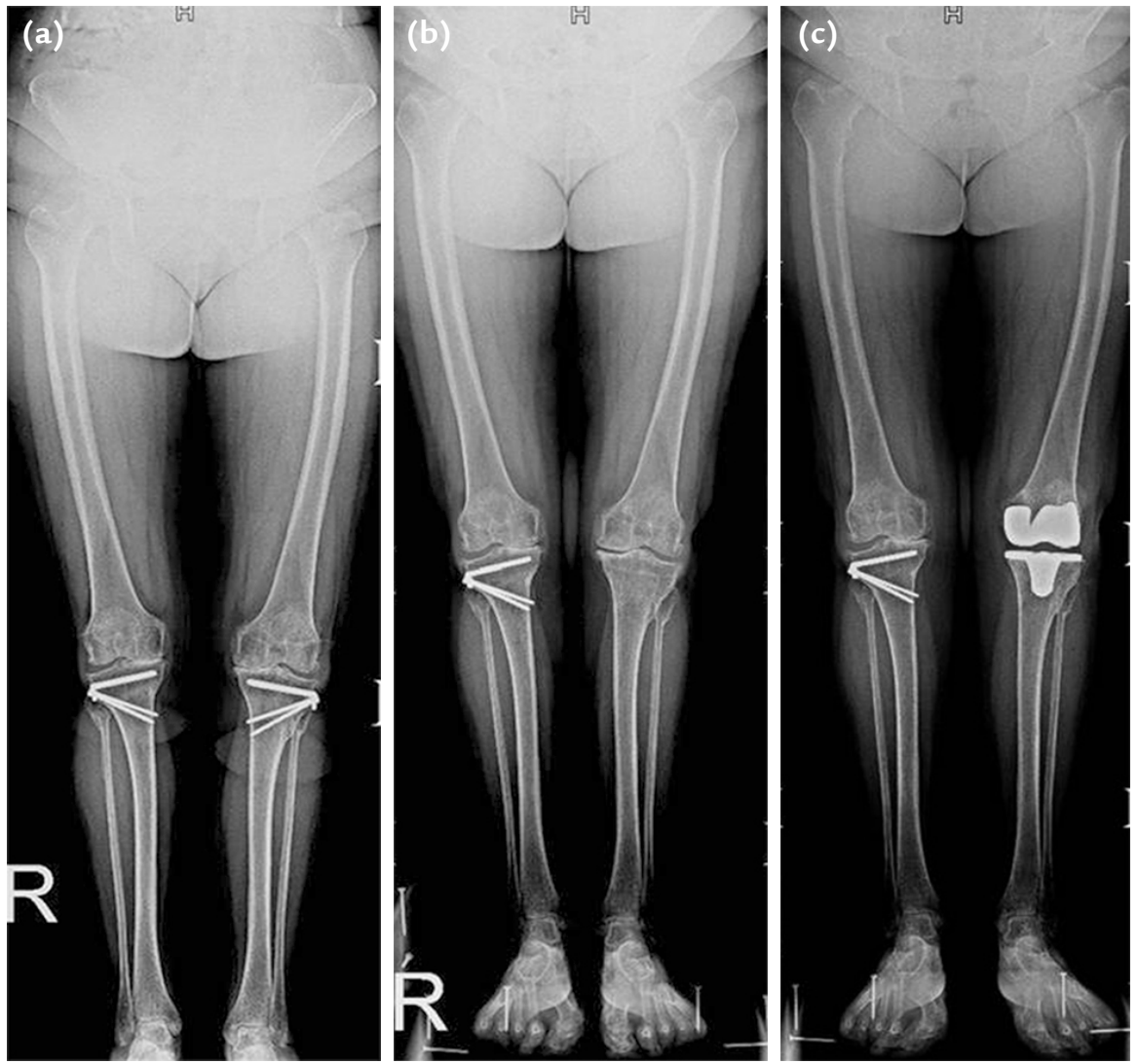

Şekil 10. a-c. Kapalı kama YTO üstü TDP uygulanmış olgunun bacak uzunluk grafileri. Farklı seanslarda uygulanmış bilateral kapalı kama YTO sonrası (a). Sol tarafta implantın çıkarılmış olduğu görülüyor (b). Sol tarafa TDP uygulanmış olduğu görülüyor (c). yapılanlarda \%92,6; YTO yapılmadan TDP yapılanlarda \%97,6; uzun dönemli (>10 yıl) sağkalım oranlarıysa sırasıyla \%93,6 ve \%95,5 olarak bulunmuştur. ${ }^{[20]}$ YTO sonrası TDP uygulamalarının sağkalımlarının değerlendirildiği en geniş seri El-Galaly ve arkadaşlarına aittir. Danimarka Diz Artroplasti Kayıt Sistemi verilerinin değerlendirildiği bu çalışmada; 1044 YTO sonrası TDP olgusunu değerlendirdikleri serilerinde 10 yıllık protez sağkalımı \%91, primer TDP uygulanan olgulardaysa (63763 olgu) \%94'tür. ${ }^{[21]}$ Bu sonuçlara göre revizyon TDP için ham risk oranı YTO geçirmiş olgularda 1,73 kat daha fazla bulunmuş olmakla birlikte, cinsiyet ve yaşa göre ayarlama yapıldığında risk oranı 1,19'a düşmüştür. Her iki grupta kısıtlayıcı implant seçimi benzer oranlarda bulunmuştur. Buna ek olarak, posterior stabilize TDP seçimi yine iki grupta da daha düşük sağkalım oranlarıyla ilişkilidir. YTO sonrası posterior stabilize TDP kullanılan olgularda bağ koruyanlara göre düzeltilmiş revizyon riski oranı 1,46 olarak hesaplanmıştır. ${ }^{[21]}$ Yoon ve arkadaşları ise kadın cinsiyet ve obeziteye ek olarak komorbiditelerin, diyabet, osteporoz ve hiperlipidemi varlığının revizyon oranlarını arttırdığını göstermişlerdir. ${ }^{[22]}$
Protez sağ kalım sürelerinin göreceli daha kısa olması izole medial kompartman artrozu olan ve YTO için uygun olan hasta grubunda cerrahları unikompartmantal diz protezine veya TDP'ye yönlendirmemelidir. Her ne kadar sağ kalım oranları azalmış olsa da asıl amacın TDP'yi geciktirmek olduğu unutulmamalıdır. [23] TDP sonrası oluşabilecek bir revizyon ihtiyacında kemik stok kaybı ve revizyon ameliyatının morbiditesi YTO sonrası uygulanan artroplastiye göre çok fazladır. Unikompartmantal diz protezinden ve YTO'dan TDP'ye revize edilen olguların değerlendirildiği çalışmaların meta-analizinde klinik sonuçların benzer olduğu ortaya konmuştur. TDP'de kullanılan implantlar değerlendirildiğinde, unikompartmantal diz protezi sonrası YTO'ya göre daha kalın polietilen ve daha fazla revizyon komponent kullanım gerekliliği olduğu bulunmuştur. ${ }^{[24]}$ YTO sonrası TDP sonuçlarını primer TDP sonuçlarıyla değil, revizyon TDP sonuçları ile karşılaştırmak daha doğru görünmektedir.

Açık kama YTO ve kapalı kama YTO sonrası uygulanan artroplasti olgularının değerlendirildiği çalışmalarda ise klinik ve radyolojik sonuçlar arasında farklılık olmadığı gösterilmiştir. Bu olgularda revizyon 

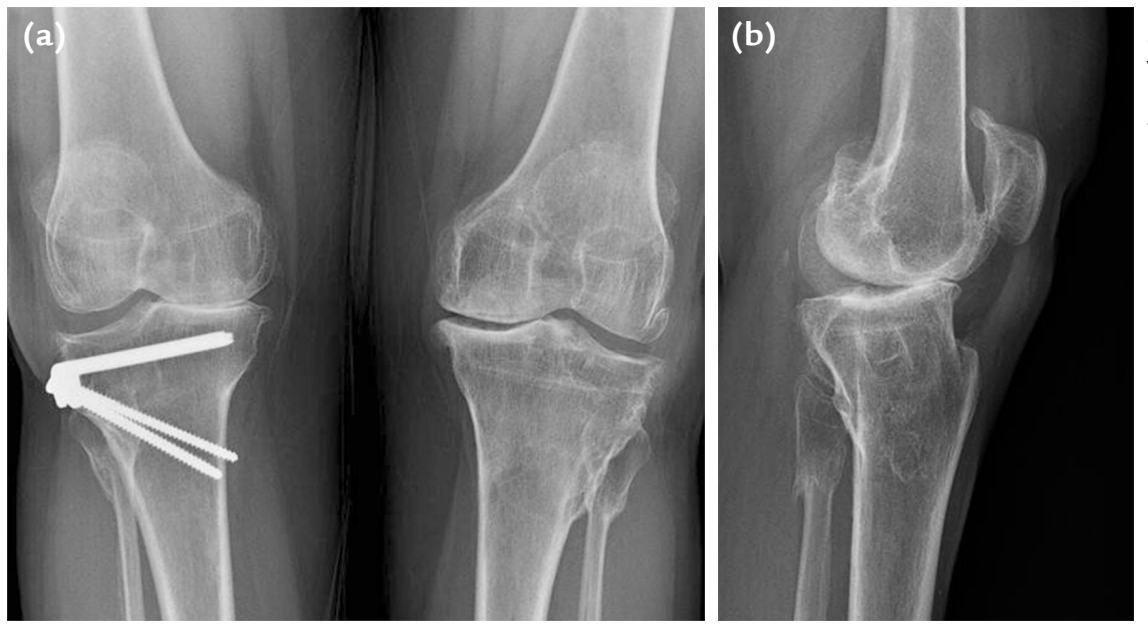

Şekil 11. a-d. Şekil 10'daki kapalı kama YTO olgusunun TDP öncesi ve sonrası grafileri. Yüklenmede ön arka ve grafide sol dizde proksimal tibia geometrisindeki değişiklikler görülüyor (a, b). Sol tarafın ameliyat sonrası ön-arka ve yan grafileri (c, d).
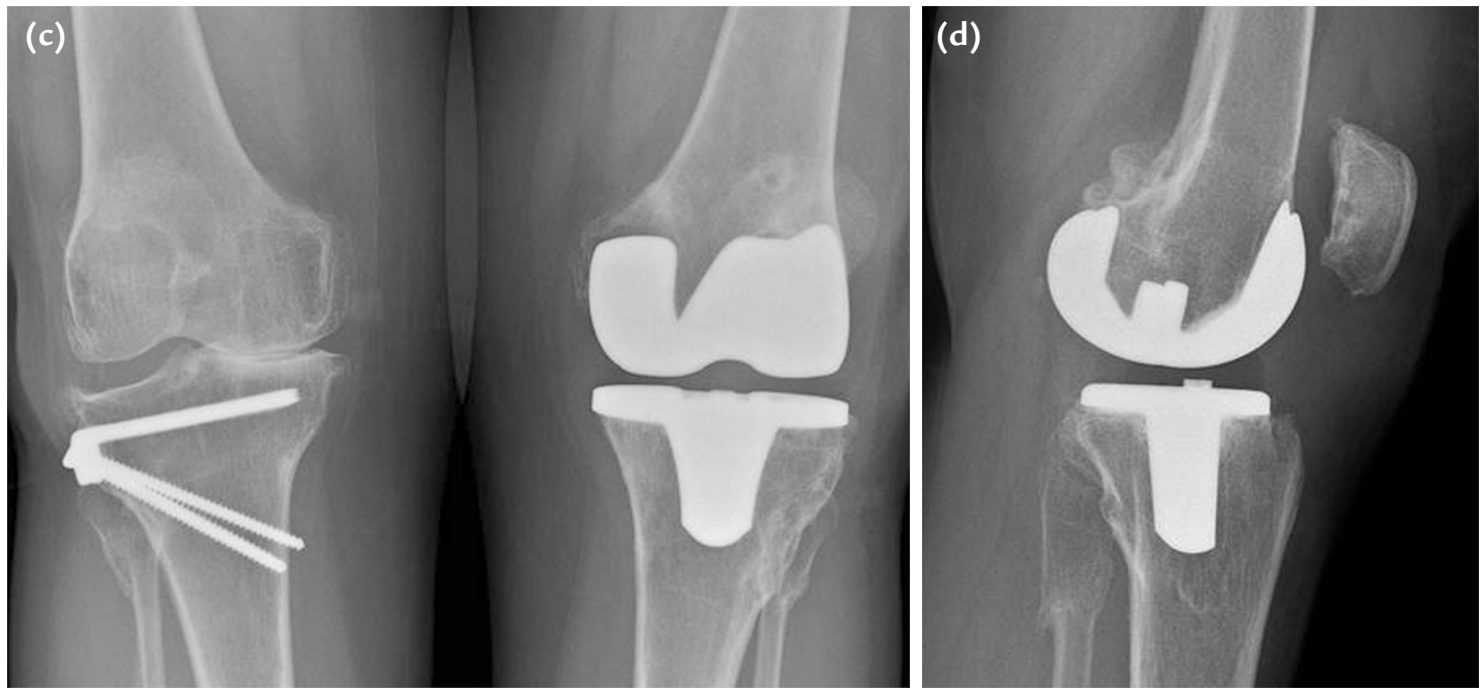

oranlarının da benzer olduğu gösterilmiştir. ${ }^{[9,12]}$ Ancak kapalı kama YTO sonrası değişen patellofemoral kinematik ve değişen proksimal tibia metafiz geometrisine bağı ek yumuşak doku girişim gerekliliğinin arttığı gösterilmiştir.

\section{Komplikasyonlar}

YTO sonrası TDP uygulamalarında, primer artroplasti sonrası görülen komplikasyonlara benzer; enfeksiyon, aseptik gevşeme, sertlik, instabilite gibi komplikasyonlar görülebilmektedir. Özellikle artroplasti sırasında ekstremitede dizilim bozukluğunun olması, kadın cinsiyet ve artmış kilonun erken gevşeme için osteotominin tipinden bağımsız olarak risk faktörü olduğu düşünülmektedir. ${ }^{[25]}$

Farfalli ve arkadaşları incelemiş oldukları 31 hastalık serilerinde kapalı kama YTO sonrası TDP uygulamalarında toplam komplikasyon oranlarını \%35 olarak belirtmişlerdir. ${ }^{[26]}$ Bu çalışmadaki karşılaşılan komplikasyonların sertlik, derin enfeksiyon, aseptik gevşeme, patellofemoral subluksasyon, instabilite ve açıklanamayan ağrı olduğu görülmektedir. Bu denli artmış komplikasyon oranları kapalı YTO sonrası bağ dengesini tekrar oluşturmakta olan zorluk veya dizilimi düzeltmek için yapılan fazla kesilere bağlı olarak düşünülmektedir. Ayrıca artmış enfeksiyon oranlarının geçirilmiş operasyonlara bağlı olduğu düşünülmektedir (Tablo 1).

Çok merkezli retrospektif bir çalışmada açık ya da kapalı kama sonrası TDP yapılmış ve minimum beş yıl süreyle izlenmiş 135 olgu incelendiğinde erken dönem (<3 ay) komplikasyon oranları arasında anlamlı bir fark bulunmamakla birlikte bu oran açık kama grubunda \%12,3, kapalı kama grubundaysa \%8,3'tür. Cilt nekrozu, peroneal ya da posterior tibial sinir hasarı, 
Tablo 1. YTO sonrası TDP uygulanan hastaları inceleyen çalışmalardaki görülen komplikasyonlar

\begin{tabular}{|c|c|c|}
\hline Çalışma başlıca yazarı yayımlanma yılı & Hasta sayısı & Komplikasyonlar ve oranları \\
\hline Efe ve ark. ${ }^{[27]}, 2010$ & 41 & $\begin{array}{l}\text { - Cilt nekrozu }(\% 9,7) \\
\text { - Hareket kısıtlı̆̆ı }(\% 4,8) \\
\text { - Yüzeyel enfeksiyon }(\% 2,4) \\
\text { - Venöz tromboz }(\% 2,4)\end{array}$ \\
\hline Farfalli ve ark. ${ }^{[26]}, 2012$ & 31 (34 diz) & $\begin{array}{l}\text { - Implant çevresi radyolüsen hat (\%6) } \\
\text { - Hareket kısıtlığı (\%12) } \\
\text { - Aseptik gevşeme (\%6) } \\
\text { - Patellofemoral subluksasyon (\%3) } \\
\text { - Instabilite (\%3) } \\
\text { - Derin enfeksiyon (\%8) } \\
\text { - Açıklanamayan ağrı (\%3) }\end{array}$ \\
\hline Niinmaki ve ark.[18], 2014 & 1036 & $\begin{array}{l}\text { - Revizyon oranı (\%9) } \\
\text { - Revizyon nedenleri } \\
\text { Dizilim bozukluğu }(\% 19,3) \text {, derin enfeksiyon }(\% 16,9) \text {, aseptik } \\
\text { gevşeme }(\% 10,8) \text {, patellar komplikasyonlar }(\% 9,6) \text {, periprostetik } \\
\text { kırık }(\% 1,2)\end{array}$ \\
\hline Amendola ve ark. ${ }^{[16]}, 2010$ & 24 (28 diz) & $\begin{array}{l}\text { - Hareket kısıtlığı }(\% 3,5) \\
\text { - Patellar yüzey değişimi gerektirecek diz önü ağrısı }(\% 10,7)\end{array}$ \\
\hline
\end{tabular}

polietilen dislokasyonu, enfeksiyon, eklem sertliği bu komplikasyonlar arasında yer almaktadır. Geç dönem (>3 ay) komplikasyonlar gevşeme $(\% 5,5)$ ve enfeksiyonu $(\% 3,6)$ kapsamakta ve kapalı kama grubunda geç dönem komplikasyonlarla anlamlı olarak daha sık karşılaşılmaktadır (kapalı kama YTO: \%12, açık kama YTO: \%6). ${ }^{[28]}$

\section{BiZiM DENEYIMIMIZ}

Kliniğimizde 1993-2018 yılları arasında 37 YTO (19 kapalı kama, 17 kubbe, bir açık kama tipi) TDP'ye dönüştürülmüştür. TDP, YTO'dan ortalama $9,11 \pm 4,14$ yıl sonra yapılmıştır. Bu hastaların yaş ortalaması, TDP öncesinde $68,51 \pm 5,69^{\prime}$ dur. TDP'den önce mekanik eksen sapması $12,26^{\circ} \pm 7,41^{\circ}$ (varus), TDP'den sonraysa $4,17^{\circ} \pm 2,71^{\circ}$ (varus) ölçülmüştür. Frontal ve sagittal planlarda femoral komponent açıları $94,42^{\circ} \pm 5,69^{\circ}$ ve $3,39^{\circ} \pm 5,20^{\circ}$; frontal ve sagittal planlarda tibial komponent açıları $89,94^{\circ} \pm 4,15^{\circ}$ ve $3,03^{\circ} \pm 4,76^{\circ}$ 'dir. Olguların $\% 32,4^{\prime}$ üne $(n=12)$ lateral retinaküler gevşetme gerekmiştir; olguların $\% 16,2$ 'sinde $(n=6)$ tibial tüberkül osteotomisi yapılmıştır. Yedi olguda $(\% 18,9)$, uzatma stemli protez kullanılmıştır. ${ }^{[29]}$

Bizim deneyimimize göre; YTO, TDP gereksinimini ortalama dokuz yıl erteletmiştir. Öncesinde YTO yapılmış olması protezin uygun pozisyonda yerleştirilmesine engel olmamaktadır. YTO öyküsünün olması, TDP'de genişletilmiş yaklaşım ya da stemli protez kullanım gereksinimiyle ilişkili görünmektedir.

\section{SONUÇ}

YTO, genç, aktif, izole medial kompartman osteoartriti olan olgularda tercih edilebilecek bir tedavi yöntemidir. Birçok olguda TDP gerekliliğini ortadan kaldırmakta; TDP gereken olgulardaysa bu gereksinimi yaklaşık 10 yıl süreyle geciktirebilmektedir. YTO sonrası TDP uygulanması kendine özgü teknik özelliklere sahiptir; bu özellikler göz önünde bulundurularak, iyi bir ameliyat öncesi hazırlıkla ameliyata girilmelidir. Patellanın döndürülmesi, patellar yüksekliğin değişmiş olması ve proksimal tibia geometrisinin bozulmuş olması ile ilgili sorunlar yaşanabileceği bilinmelidir. Klinik sonuçlar ve komplikasyon oranları bakımından öncesinde YTO uygulanan ve uygulanmayan TDP'ler arasında anlamlı bir fark gözlenmemektedir. YTO sonrası TDP uygulanan olgularda protez sağkalımı YTO'suz TDP yapılanlara göre daha düşük bulunmuş olmakla birlikte uzun dönemli (>10 yıl) sağkalım oranları \%90'ların üzerinde seyretmektedir. İzole medial kompartman artrozu olan genç, aktif bireylerin cerrahi tedavisinde YTO geçerli bir yöntemdir; ilerde uygulanma olasılı̆̆ı olan TDP üzerine olumsuz bir etkisi olduğu gösterilmemiştir. 


\section{KAYNAKLAR}

1. Cerciello S, Vasso M, Maffulli N, Neyret P, Corona K, Panni AS. Total knee arthroplasty after high tibial osteotomy. Orthopedics 2014;37(3):191-8. Crossref

2. Insall JN, Joseph DM, Msika C. High tibial osteotomy for varus gonarthrosis. A long-term follow-up study. J Bone Joint Surg Am 1984;66(7):1040-8. Crossref

3. Flecher X, Parratte S, Aubaniac JM, Argenson JN. A 12-28year follow-up study of closing wedge high tibial osteotomy. Clin Orthop Relat Res 2006;452:91-6. Crossref

4. Hui C, Salmon LJ, Kok A, Williams HA, Hockers N, van der Tempel WM, Chana R, Pinczewski LA. Long-term survival of high tibial osteotomy for medial compartment osteoarthritis of the knee. Am J Sports Med 2011;39(1):64-70. Crossref

5. Mont MA, Antonaides S, Krackow KA, Hungerford DS. Total knee arthroplasty after failed high tibial osteotomy. A comparison with a matched group. Clin Orthop Relat Res 1994;(299):125-30. Crossref

6. Keenan OJF, Clement ND, Nutton R, Keating JF. Older age and female gender are independent predictors of early conversion to total knee arthroplasty after high tibial osteotomy. Knee 2019;26(1): 207-12. Crossref

7. Khoshbin A, Sheth U, Ogilvie-Harris D, Mahomed N, Jenkinson R, Gandhi R, Wasserstein D. The effect of patient, provider and surgical factors on survivorship of high tibial osteotomy to total knee arthroplasty: a population-based study. Knee Surg Sports Traumatol Arthrosc 2017;25(3):88794. Crossref

8. Vince KG, Abdeen A. Wound problems in total knee arthroplasty. Clin Orthop Relat Res 2006;452:88-90. Crossref

9. Bastos Filho R, Magnussen RA, Duthon V, Demey G, Servien E, Granjeiro JM, Neyret P. Total knee arthroplasty after high tibial osteotomy: a comparison of opening and closing wedge osteotomy. Int Orthop 2013;37(3):427-31. Crossref

10. Gill T, Schemitsch EH, Brick GW, Thornhill TS. Revision total knee arthroplasty after failed unicompartmental knee arthroplasty or high tibial osteotomy. Clin Orthop Relat Res 1995;(321):10-8. Crossref

11. Song SJ, Bae DK, Kim KI, Lee CH. Conversion Total Knee Arthroplasty after Failed High Tibial Osteotomy. Knee Surg Relat Res 2016;28(2):89-98. Crossref

12. Han JH, Yang JH, Bhandare NN, Suh DW, Lee JS, Chang YS, Yeom JW, Nha KW. Total knee arthroplasty after failed high tibial osteotomy: a systematic review of open versus closed wedge osteotomy. Knee Surg Sports Traumatol Arthrosc 2016;24(8):2567-77. Crossref

13. Neyret P, Deroche P, Deschamps G, Dejour H. [Total knee replacement after valgus tibial osteotomy. Technical problems]. Rev Chir Orthop Reparatrice Appar Mot 1992;78(7):438-48.

14. Hernigou P, Duffiet $P$, Julian D, Guissou I, Poignard A, Flouzat-Lachaniette $\mathrm{CH}$. Outcome of total knee arthroplasty after high tibial osteotomy: does malalignment jeopardize the results when using a posterior-stabilized arthroplasty? HSS J 2013;9(2):134-7. Crossref

15. Akasaki Y, Matsuda S, Miura H, Okazaki K, Moro-oka TA, Mizu-uchi H, Iwamoto Y. Total knee arthroplasty following failed high tibial osteotomy: mid-term comparison of posterior cruciate-retaining versus posterior stabilized prosthesis. Knee Surg Sports Traumatol Arthrosc 2009;17(7):795-9. Crossref
16. Amendola A, Bonasia DE. Results of high tibial osteotomy: review of the literature. Int Orthop 2010;34(2):155-60. Crossref

17. Meding JB, Keating EM, Ritter MA, Faris PM. Total knee arthroplasty after high tibial osteotomy. A comparison study in patients who had bilateral total knee replacement. J Bone Joint Surg Am 2000;82(9):1252-9. Crossref

18. Niinimäki $T$, Eskelinen $A$, Ohtonen $P$, Puhto AP, Mann BS, Leppilahti J. Total knee arthroplasty after high tibial osteotomy: a registry-based case-control study of 1,036 knees. Arch Orthop Trauma Surg 2014;134(1):73-7. Crossref

19. Ramappa M, Anand S, Jennings A. Total knee replacement following high tibial osteotomy versus total knee replacement without high tibial osteotomy: a systematic review and meta analysis. Arch Orthop Trauma Surg 2013;133(11):1587-93. Crossref

20. Seo SS, Nha KW, Kim TY, Shin YS. Survival of total knee arthroplasty after high tibial osteotomy versus primary total knee arthroplasty: A meta-analysis. Medicine (Baltimore) 2019;98(30):e16609. Crossref

21. El-Galaly A, Nielsen PT, Jensen SL, Kappel A. Prior High Tibial Osteotomy Does Not Affect the Survival of Total Knee Arthroplasties: Results From the Danish Knee Arthroplasty Registry. J Arthroplasty 2018;33(7):2131-5.e1. Crossref

22. Yoon JR, Ko SN, Jung KY, Lee Y, Park JO, Shin YS. Risk of Revision Following Total Knee Arthroplasty or High Tibial Osteotomy: A Nationwide Propensity-Score-Matched Study. J Bone Joint Surg Am 2019;101(9):771-8. Crossref

23. Robertsson $\mathrm{O}, \mathrm{W}$-Dahl A. The risk of revision after TKA is affected by previous HTO or UKA. Clin Orthop Relat Res 2015;473(1):90-3. Crossref

24. Lee YS, Kim HJ, Mok SJ, Lee OS. Similar Outcome, but Different Surgical Requirement in Conversion Total Knee Arthroplasty following High Tibial Osteotomy and Unicompartmental Knee Arthroplasty: A Meta-Analysis. J Knee Surg 2019;32(7):686-700. Crossref

25. Parvizi J, Hanssen AD, Spangehl MJ. Total knee arthroplasty following proximal tibial osteotomy: risk factors for failure. J Bone Joint Surg Am 2004;86(3):474-9. Crossref

26. Farfalli LA, Farfalli GL, Aponte-Tinao LA. Complications in total knee arthroplasty after high tibial osteotomy. Orthopedics 2012;35(4):e464-8. Crossref

27. Efe T, Heyse TJ, Boese C, Timmesfeld N, Fuchs-Winkelmann S, Schmitt J, Theisen C, Schofer MD. TKA following high tibial osteotomy versus primary TKA-a matched pair analysis. BMC Musculoskelet Disord 2010;11(1):207. https://bmcmusculoskeletdisord.biomedcentral.com/ articles/10.1186/1471-2474-11-207

28. Ehlinger $\mathrm{M}$, D'Ambrosio A, Vie P, Leclerc S, Bonnomet $\mathrm{F}$, Bonnevialle P, Lustig S, Parratte S, Colmar M, Argenson JN. Total knee arthroplasty after opening- versus closing-wedge high tibial osteotomy. A 135-case series with minimum 5-year follow-up. Orthop Traumatol Surg Res 2017;103(7):1035-9. Crossref

29. Kaya Bicer E, Al-Jasim OAA, Ozcan K, Aydogdu S, Sur H. Total Knee Arthroplasty After High Tibial Osteotomy: Is Component Positioning Affected? 20th EFORT Annual Congress Lisbon, 5-7/05/2019, Poster Sunumu 